Journal of Accident and Emergency Medicine 1994 11, 250-252

\title{
Post-traumatic transient cortical blindness in children: a report of four cases and a review of the literature
}

\author{
A.P.GLEESON \& T.F.BEATTIE
}

Accident and Emergency Department, Royal Aberdeen Children's Hospital, Cornhill Road, Aberdeen AB9 2ZG

\section{SUMMARY}

Four cases of transient cortical blindness following head injury in children are described. The theories regarding the pathophysiology of the condition are discussed and advice regarding management of such cases is given.

Key words: diagnosis, head injury, transient cortical blindness

\section{INTRODUCTION}

Transient cortical blindness following head injury is a well documented clinical entity that is most commonly seen in children. However, there is still a certain lack of awareness in accident and emergency (A\&E) departments regarding this condition. The visual loss is not uncommonly attributed to hysteria on the part of the patient. We report four cases with a review of the literature.

\section{CASE 1}

A 5-year-old male presented to the A\&E department of Royal Aberdeen Children's Hospital following a fall from a swing in which he sustained a frontal head injury. Thirty minutes after this incident he stated that he could not see. There had been no loss of consciousness but he was somewhat confused and he complained of nausea, lethargy and malaise. On examination he was crying and extremely agitated. His pulse rate was 110 beats $\min ^{-1}$, BP 105/60 and his Glasgow Coma Scale (GCS) was 14. The left pupil was dilated in comparison with the right but both reacted normally to light. He showed no perception of light and he did not respond to threatening gestures. Fundoscopy was normal and there were no other abnormalities evident. A skull radiograph was normal and the patient was admitted for observation. A consultation with an ophthalmologist confirmed our findings and $2 \mathrm{~h}$ following admission the patient had regained normal vision.

\section{CASE 2}

A 9-year-old boy sustained a right frontal head injury after a fall from a tree. There was uncertainty concerning a history of loss of consciousness and he complained of nausea and malaise. Twenty minutes following the accident he complained of complete visual loss. On examination his pulse and blood pressure were within the normal range but his GCS was 13. His right pupil was fixed and dilated but it was noted that he had been documented as having a hyphaema and a traumatic mydriasis following an eye injury some months previously. Again he was clinically blind and fundoscopy was normal. A skull radiograph was normal and, in view of his reduced GCS, he had a CT brain scan which was also normal. Two hours after admission he regained normal vision.

\section{CASE 3}

A 6-year-old male developed complete visual loss 20 minutes following a parieto-occipital head injury. At presentation to the A\&E department he was disorientated, uttering incomprehensible sentences and he had a GCS of 13. He was clinically blind, had normal reacting pupils but, again, fundoscopy was normal. Both a skull radiograph and a CT brain scan were normal and $6 \mathrm{~h}$ following the incident he had regained normal vision. His recovery beyond this was uneventful.

\section{CASE 4}

A 13-month-old boy fell approximately 4 feet from a 
A.P. Gleeson \& T.F. wall, striking his occiput on the concrete below. Beattie There was no loss of consciousness and $20 \mathrm{~min}$ following the incident his parents noticed that the child was lying quietly on his bed staring up at the roof light and he was not responding to them. He also vomited on four occasions. On examination in hospital, the child had a GCS of 12 and he did not respond to verbal stimuli or threatening gestures but he cried in response to a pen torch being shone in his eyes. Pupillary reactions were normal and there were no lateralizing signs. A skull radiograph was normal and $2 \mathrm{~h}$ after the incident he was behaving normally and was reacting appropriately to visual stimuli.

At follow up all children were well with no sequelae.

\section{DISCUSSION}

Post-traumatic transient cortical blindness (PTTCB) following head injury is a distinct phenomenon which was first described by Bodian ${ }^{1}$ when he reported six cases in children. This transient visual loss follows an apparently minor head injury with occipital trauma being the most frequent cause $(60 \%)$. The incidence of PTTCB is thought to be as high as $0.4-0.6 \%$. $^{2}$ However, it has been suggested that it may be more common than this as the visual loss may be attributed to hysteria, or the child may be too young to complain of visual loss and his/her unco-operative agitated state would be assumed to have occurred because of the frightening situation that the child was experiencing. ${ }^{3}$ Visual loss may be incomplete, (Case 4) and transient pupillary (Case 1) and extraocular abnormalities, including upgoing plantars, have been described. ${ }^{1,2,4,5}$

The differential diagnoses range from hysterical blindness and commotio retinae to cerebral contusion, intra-cranial haematoma, and optic nerve or chiasmal injury. A patient with hysterical blindness will blink and/or withdraw in response to threatening gestures and optokinetic nystagmus will be present. This latter phenomenon is elicited by passing a sheet of paper with alternating light and dark vertical strips in front of the patient's eyes. A lack of nystagmus in response to this is consistent with blindness as optokinetic-induced nystagmus cannot be suppressed voluntarily.

The majority of cases of PTTCB resolve within a matter of hours, although, some prolonged syndromes have been described. ${ }^{6}$

There has been considerable debate concerning spasm within the pre-geniculate area i.e., optic nerve, chiasm or tracts, with there being no cortical lesion per se. This vasospasm would explain the pupillary and extra-occular abnormalities that have been observed as well as the quite sudden, sometimes immediate, visual loss and the brief nature of the complaint. Notably, PTTCB is more common in children who, as a group, have a more labile vasculature than adults. ${ }^{1}$ An associated condition, 'footballer's migraine ${ }^{77}$ also has a vasospastic theory of origin. In this condition, patients developed transient neurological symptoms, including visual disturbance, leading to migrainous headache after they headed a football. Other evidence which supports a vascular cause for PTTCB is that there appears to be an increased incidence of migraine in patients both before and after an episode of PTTCB, ${ }^{2}$ and that a cortical visual disturbance has been described in a patient with brain herniation when the posterior cerebral vessels were compressed against the edge of the tentorium. ${ }^{8}$

The alternative explanation for PTTCB is that of a localized occipital contusion causing focal cortical oedema and ischaemia. This proposed tissue oedema is not visible macroscopically as CT brain scans of patients with PTTCB are normal (Cases 2 and 3). The fact that most cases of PTTCB develop after a short period of normal vision is consistent with this theory but, it falters when one considers that some cases develop immediately following the injury. Patients with PTTCB may also demonstrate occipital slowing of the alpha waves on the EEG, ${ }^{9}$ although the significance of this is uncertain as occipital slowing frequently occurs after head injury irrespective of the anatomical site of the insult. Other features in favour of a cerebral origin are reported cases of aphasia, perseveration, patchy visual loss, palinopsia (persistence of a visual image after the stimulus has gone) and Anton's syndrome (denial of blindness).

A patient presenting with blindness following a head injury should be given a full neurological examination and a skull radiograph and the case should be discussed with a neurosurgeon. Should the history or clinical findings (low or deteriorating level of consciousness, other focal neurological signs) suggest a significant primary brain injury or the development of a treatable secondary complication such as an intra-cranial haematoma then an urgent CT scan should be performed. PTTCB requires no treatment beyond standard in-patient neurological observation and spontaneous resolution of normal vision within $24 \mathrm{~h}$ is the norm. 


\section{ACKNOWLEDGEMENT}

I would like to thank Ms V. Bell for typing the manuscript.

\section{REFERENCES}

1. Bodian M. (1964) Transient loss of vision following head trauma. New York State Journal of Medicine 64, 912-920.

2. Greenblatt S.H. (1973) Post-traumatic transient cerebral blindness. Journal of the American Medical Association 225, 1073-1076.

3. Carmola J. \& Harris B.S. (1970) Transient cortical blindness: still an overlooked syndrome? New England Journal of Medicine 282, 1325.
4. Gjerris E. \& Mellemgaard C. (1969) Transient cortical blindness in head injury. Acta Neurologica Scandinavica 45, 623-631.

5. Yamamoto L.G. \& Bard R.D. (1988) Transient blindness following mild head trauma. Clinical Paediatrics 27, 479-483.

6. Holmes G.L. (1978) Prolonged cortical blindness after closed head trauma (letter) Southern Medical Journal 71, 612-613.

7. Matthews W.B. (1972) Footballers Migraine. British Medical Journal 2, 326-327.

8. Hoyt W.F. (1960) Vascular lesions of the visual cortex with brain herniation through the tentorial incisura. Archives of Ophthalmology 64, 44-57.

9. Griffith J.F. \& Dodge P.R. (1968) Transient blindness following head injury in children. New England Journal of Medicine 278, 648-651. 